\title{
Identification of Surface Processes in Individual Minerals of a Complex Ore through the Analysis of Polished Sections Using Polarization Microscopy and X-ray Photoelectron Spectroscopy (XPS)
}

\author{
Dhamelyz Silva-Quiñones $\left.{ }^{1,2}{ }^{(}\right)$, Chuan $\mathrm{He}^{2}$, Melissa Jacome-Collazos ${ }^{1}$, Carsten Benndorf ${ }^{1,3}{ }^{(\mathbb{D}}$, \\ Andrew V. Teplyakov ${ }^{2}$ and Juan Carlos F. Rodriguez-Reyes ${ }^{1, *(D)}$ \\ 1 Department of Bioengineering and Chemical Engineering, Universidad de Ingeniería y Tecnología-UTEC, \\ Jr. Medrano Silva 165, Lima 04, Peru; dsilvaq@udel.edu (D.S.-Q.); melissajacome6@gmail.com (M.J.-C.); \\ benndorf@chemie.uni-hamburg.de (C.B.) \\ 2 Department of Chemistry and Biochemistry, University of Delaware, Newark, DE 19716, USA; \\ river@udel.edu (C.H.); andrewt@udel.edu (A.V.T.) \\ 3 Institute of Physical Chemistry, Department of Chemistry, University of Hamburg, Bundesstr. 45, \\ D-20146 Hamburg, Germany \\ * Correspondence: jcrodriguez@utec.edu.pe; Tel.: +51-1-230-5000 (ext. 4220)
}

Received: 10 September 2018; Accepted: 26 September 2018; Published: 28 September 2018

\begin{abstract}
Understanding the changes of a mineral during ore processing is of capital importance for the development of strategies aimed at increasing the efficiency of metal extraction. This task is often difficult due to the variability of the ore in terms of composition, mineralogy and texture. In particular, surface processes such as metal re-adsorption (preg-robbing) on specific minerals are difficult to evaluate, even though they may be of importance as the re-adsorbed material can be blocking the valuable mineral and negatively affect the extraction process. Here, we show a simple yet powerful approach, through which surface processes in individual minerals are identified by combining polarization microscopy (MP) and X-ray photoelectron spectroscopy (XPS). Taking as an example a silver-containing polymetallic sulfide ore from the Peruvian central Andes (pyrite-based with small amounts of galena), we track the changes in the sample during the course of cyanidation. While polarization microscopy is instrumental for identifying mineralogical species, XPS provides evidence of the re-adsorption of lead on a pyrite surface, possibly as lead oxide/hydroxide. The surface of pyrite does not show significant changes after the leaching process according to the microscopic results, although forms of oxidized iron are detected together with the re-adsorption of lead by XPS. Galena, embedded in pyrite, dissolves during cyanide leaching, as evidenced by PM and by the decrease of XPS signals at the positions associated with sulfide and sulfate. At the same time, the rise of a lead peak at a different position confirms that the re-adsorbed lead species cannot be sulfides or sulfates. Interestingly, lead is not detected on covellite surfaces during leaching, which shows that lead re-adsorption is a process that depends on the nature of the mineral. The methodology shown here is a tool of significant importance for understanding complex surface processes affecting various minerals during metal extraction.
\end{abstract}

Keywords: leaching; cyanide; pyrite; polarization microscopy; XPS; surface; re-adsorption

\section{Introduction}

Understanding the metallurgical behavior of an ore is key in determining the viability of a project in mineral processing. Ore characterization is important not only for making a correct assessment of 
reserves and resources, but also for exploring novel processing strategies [1]. Polarization microscopy $(\mathrm{PM})$ is a characterization technique that differentiates minerals based on their different optical properties under polarized light. Minerals with transition metals will have characteristic reflection indexes; other minerals (such as carbonates and silicates) do not reflect light and appear opaque. Thin sections of the latter minerals, however, are transparent to transmitted light, while the first group of minerals are non-transparent. Thus, by combining experiments with reflected and transmitted polarized light, this technique allows for the identification of textures, alterations, intergrowths, among other characteristics of the mineral [2]. This technique is often complemented by more detailed microscopies, such as scanning electron microscopy (including its variant for quantitative evaluation of minerals, QEM-SCAN), which together provide complete information regarding the mineralogical composition of ores. Applied to different stages of a metallurgical process, these techniques allow for a better understanding of the effect of such process on specific minerals within the ore [3].

Since techniques for mineralogical characterization often analyze information over a few micrometers within the mineral, surface-related processes are rarely detected. This is a significant drawback, considering that important metallurgical processes occur at the topmost layers of minerals. For example, preg-robbing is a detrimental process through which a metal is re-adsorbed after it has been successfully leached [4]. X-ray photoelectron spectroscopy (XPS) has a depth sensitivity on the order of $10 \mathrm{~nm}$ and provides information on the oxidation states and the chemical environment of different elements on a surface. There have been several investigations relying on XPS to obtain information regarding surface transformation of individual, pure minerals [5-8]. Even though this strategy provides important information regarding surface processes, many processes occur only when one mineral is in the presence of another. One of the best known examples of this is the formation of galvanic pairs, where a stable mineral (such as pyrite) can promote the dissolution of a more reactive mineral (such as sphalerite) $[9,10]$. Another example is the formation of passivating layers that can hinder the metal extraction by blocking the surface. For example, passivation may involve the formation of surface by-products (formation of sulfur during the oxidation of sulfide minerals) or the re-adsorption of dissolved metal ions (preg-robbing of $\mathrm{AuCN}_{(\mathrm{ads})}$ hinders the cyanidation) [11,12]. Since passivating layers may be as thin as a few atomic layers, identification of these species is a difficult task with traditional mineralogical techniques, and it is in these cases that XPS can provide the most valuable information [13].

Here, a method to identify surface processes occurring on surfaces of specific minerals within a complex ore is presented. By using a polished section of minerals embedded into a resin, minerals within the section are identified with polarization microscopy and their surfaces are characterized with XPS. The same characterization tools are employed after the sample is subjected to a hydrometallurgical process (leaching with cyanide). The matrix responds well to the leaching medium and is compatible with ultra-high vacuum conditions, which allows us to use both techniques, namely XPS and PM, on the same samples [14].

\section{Materials and Methods}

The ore sample analyzed was generously donated by Volcan Cia. Minera, and is a polymetallic sulfide from the Central Andes of Peru which enters a leaching circuit for extracting silver. The ore composition is mainly pyrite $\left(\mathrm{FeS}_{2}\right)$, associated with galena ( $\left.\mathrm{PbS}\right)$, covellite $(\mathrm{CuS})$ and sphalerite $(\mathrm{ZnS})$, as well as with sulfosalts of copper and silver. The ore also contains non-metallic minerals, such as carbonates and silicates. The analysis via inductively-coupled plasma mass spectrometry (ICP-MS) shows a composition of 45.2 wt.\% S, 37.1 wt.\% Fe, Pb (4487 ppm), Cu (992 ppm), Zn (807 ppm) and Ag (136 ppm). The study focusing on the response of this silver-containing ore to cyanidation is a subject of a separate publication. The ore size used was mesh $+35(\approx 500 \mu \mathrm{m})$ to make identification of the minerals via PM reliable. Polished sections were prepared by embedding ore samples in an epoxy resin, which after curing was polished to ensure flatness so that it can be characterized by polarization 
microscopy and XPS. In the ultra-high vacuum system, the resin was stable at the base pressure in the XPS chamber.

For the leaching tests the polished sections were suspended by a nylon thread and immersed in $150 \mathrm{~mL}$ of cyanide solution $(2 \mathrm{~g} / \mathrm{L})$ at $\mathrm{pH} \approx 11.5$ using a magnetic stirring plate at $300 \mathrm{RPM}$ for $6 \mathrm{~h}$. The amount of cyanide was kept constant throughout the experiments, as confirmed by measuring the cyanide consumption via titration (with silver nitrate and potassium iodide as indicator, at times 15, 30, 60, 120, 180, 240 and $360 \mathrm{~min}$ ) and replenishing the amount consumed. CAUTION: Experiments with cyanide must be conducted by trained personnel and special care should be exercised, as this product is extremely poisonous. Solutions must be kept at all times at $\mathrm{pH}$ above 10 to avoid the risk of formation of gaseous hydrogen cyanide $(\mathrm{HCN})$. Ore samples and all materials exposed to cyanide should be treated with strong oxidants (bleach, hydrogen peroxide) afterwards to ensure decomposition of residual cyanide.

Polarization microscopy was performed with an OLYMPUS BX51 microscope (Olympus, Tokyo, Japan). The polished sections were marked on the back by two perpendicular axes to reproducibly locate the point chosen for analysis. The samples were analyzed in the magnification range from $5 \times$ to $100 \times$ and 4 different minerals were identified as pyrite $\left(\mathrm{FeS}_{2}\right)$, sphalerite $(\mathrm{ZnS})$, covellite $(\mathrm{CuS})$ and pyrite with inclusions of galena $(\mathrm{PbS})$. The micrographs were taken before and after a 6-h leaching.

XPS measurements were performed on a Thermo Scientific K-Alpha+ instrument (Thermo Fisher, Waltham, MA, USA) equipped with an $\mathrm{Al} \mathrm{K} \alpha$ source $(\mathrm{h} v=1486.6 \mathrm{eV})$, and a $35.3^{\circ}$ take-off angle normal to the surface was used. The pass energy used was $58.5 \mathrm{eV}$. Measurements were performed at a base pressure of $5 \times 10^{-9}$ torr. Samples were transferred from solution to the XPS chamber as fast as possible to minimize changes due to exposure to ambient. No additional cleaning was employed following the transfer. Polished sections (with the points of interested marked) were introduced into the chamber and then the points chosen were located using the built-in microscope of the XPS instrument. Figure S2 shows the identification of the minerals using PM and the camera operating in $\mathrm{UHV}$, together with the area selected for analysis (which was set to $300 \mu \mathrm{m}$ in diameter). The analysis was done before and after 30 and $360 \mathrm{~min}$ of leaching. The $\mathrm{C} 1 \mathrm{~s}$ peak at $284.6 \mathrm{eV}$ was used to calibrate all spectra. Data was collected with the software Thermo Avantage v. 5.89 (Thermo Fisher, Waltham, MA, USA) and processed with the Casa XPS software version 2.3.16 (Casa Software Ltd, Teignmouth, UK) and Origin 2017 (OriginLab, Northampton, MA, USA).

The behavior of the resin employed to prepare the polished sections in the leaching solution was followed by XPS and PM. The XPS analysis of the resin showed C, O and Si as main components, which did not change after exposure to the leaching solution (data not shown). Micrographs of the resin showed small pits in some areas, likely from a reaction with the basic medium, although they were not apparent by simple visual inspection. Even though it could be argued that species from the epoxy resin can be interfering during the mechanical preparation of samples and/or during the leaching process (which cannot be tested adequately by ex-situ XPS as C and O from ambient interfere with the measurements of epoxy resins), it will be shown here that the main surface process identified, lead re-adsorption, is also observed during the leaching of epoxy-free powdered samples.

\section{Results and Discussion}

Polarization microscopy allowed for the identification of the most representative minerals in the ore. Figure 1 shows that individual minerals, identified within a polished section with PM, can be analyzed by XPS. The presence of less-abundant minerals such as covellite and sphalerite was also confirmed by PM and XPS (Supplementary Materials, Figure S1). For XPS measurements, the assignment of species from $\mathrm{Fe}, \mathrm{S}$ and $\mathrm{Pb}$ is shown in Table 1, together with selected information available from the literature [10,15-18]. To show the reliability of the XPS signal assignments, the calibration standards are listed in the table as well for all the references cited. Despite small differences arising from different calibration standards, all the assignments of the features observed 
by XPS, especially the core level shifts and different oxidation states of the elements analyzed are not affected noticeably by these different calibration standards.

Table 1. Position of XPS signals for species relevant for this work, as obtained from the literature.

All values are given in $\mathrm{eV}$.

\begin{tabular}{|c|c|c|c|c|c|c|}
\hline Species & This Work & $\operatorname{Ref}[15]$ & Ref [10] & $\operatorname{Ref}[16]$ & Ref [17] & $\operatorname{Ref}[18]$ \\
\hline $\mathrm{S} 2 \mathrm{p}_{3 / 2}$ (Disulfide; Pyrite) & 162.0 & $162.1-162.6$ & 162.6 & - & - & - \\
\hline $\mathrm{S} 2 \mathrm{p}_{3 / 2}$ (Sulfide; Galena) & 160.7 & $160.1-160.7$ & & & & \\
\hline $\mathrm{Fe} 2 \mathrm{p}_{3 / 2}$ (Disulfide) & 706.7 & & 707.4 & - & - & - \\
\hline $\mathrm{Fe} 2 \mathrm{p}_{3 / 2}(\mathrm{O} / \mathrm{OH}$ or sulfate $)$ & 710.8 & & 711.4 & 710.8 & - & - \\
\hline $\mathrm{Pb} 4 \mathrm{f}_{7 / 2}$ (sulfide) & 137.4 & & - & - & 138.7 & - \\
\hline $\mathrm{Pb} 4 \mathrm{f}_{7 / 2}$ (sulfate) & 138.5 & & - & - & 139.4 & - \\
\hline $\mathrm{Pb} 4 \mathrm{f}_{7 / 2}$ (oxide/thiosulfate) & $138.1-138.2$ & & - & - & 138.0 & $138.0-138.1$ \\
\hline B.E. calibration & C 1s 284.6 & C1s 284.6 & $\mathrm{Au} 4 \mathrm{f}_{7 / 2} 83.9$ & C1s 284.6 & C1s 284.8 & C1s 285.1 \\
\hline
\end{tabular}

Since in Figure 1 the measurements were made over a pyrite grain, the XPS spectra of this mineral show the presence of iron and sulfur, while other metals, such as lead $(\mathrm{Pb})$, are not present. It is interesting to notice that iron features a Fe $2 \mathrm{p}_{3 / 2}$ signal at a position corresponding to sulfides (Table 1), which is consistent with the fact that sulfur features a $S 2 p_{3 / 2}$ signal with its maximum intensity around values corresponding to sulfide species $(162.0 \mathrm{eV})$. The sulfur peak seems to be composed of two pairs of signals, from which one has been attributed to disulfide and the other may be associated with polysulfides or other sulfur species in higher oxidation states [15]. No sulfate is detected in this spot, which indicates that pyrite has not been oxidized after the sample was prepared for experiments (polished), as it would be expected since pyrite is relatively stable with respect to oxidation in air [19]. After 30 min of cyanidation, however, the pyrite surface shows evidence of a reaction represented by the increase of a Fe $2 \mathrm{p}_{3 / 2}$ signal at $710.8 \mathrm{eV}$, which is attributed to oxides and/or hydroxides. The sulfur signal, however, features an increased sharpness, suggesting that species different to disulfide have been removed from the surface. The most striking finding is the appearance of lead on the pyrite surface during leaching (at surface concentrations of 5.7 and 17.4 At \% after $30 \mathrm{~min}$ and six hours, respectively), probably in the form of oxide/hydroxide or thiosulfate. Since we are focusing the study on a pyrite grain, the only explanation for the presence of lead is a two-step process, where lead is leached from particles of galena (also embedded in the polished resin sample) and it later re-adsorbs on the surface of pyrite. Senanayake [12] has considered the following equations occurring during cyanidation in presence of galena:

$$
\begin{gathered}
2 \mathrm{PbS}+6 \mathrm{CN}^{-}+\mathrm{O}_{2}+2 \mathrm{H}_{2} \mathrm{O}=2 \mathrm{CNS}^{-}+2 \mathrm{~Pb}(\mathrm{CN})_{2}+4 \mathrm{OH}^{-} \\
2 \mathrm{PbS}+2 \mathrm{CN}^{-}+\mathrm{O}_{2}+2 \mathrm{H}_{2} \mathrm{O}=2 \mathrm{CNS}^{-}+2 \mathrm{~Pb}(\mathrm{OH})_{2} \\
2 \mathrm{PbS}+2 \mathrm{CN}^{-}+\mathrm{O}_{2}+2 \mathrm{Ca}(\mathrm{OH})_{2}=2 \mathrm{CNS}^{-}+2 \mathrm{CaPbO}_{2}+2 \mathrm{H}_{2} \mathrm{O}
\end{gathered}
$$

Lead products from Equations (1)-(3) are only slightly soluble in water, so it is possible that forming lead-containing products are impregnated (re-adsorbed) on pyrite. Reactions (2) and (3) have also been proposed by Prestidge et al. [20], suggesting that plumbates $\left(\mathrm{PbO}_{2}{ }^{-2}\right)$ can finally decompose to form lead oxide, $\mathrm{PbO}$.

As the process continues for a total of six hours, the surface seems more oxidized, which is suggested by the intense Fe $2 p_{3 / 2}$ signal at $710.8 \mathrm{eV}$. No other changes are observed, as the $S 2 p_{3 / 2}$ and $\mathrm{Pb}$ 4f signals remain essentially unchanged. Polarization microscopy after leaching indicates that on a mineralogical scale no change can be identified, so lead re-adsorption seems to be a surface-related process, probably taking place over a scale of a few nanometers. 


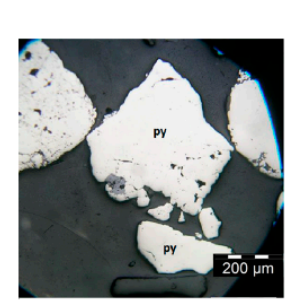

Pyrite before leaching
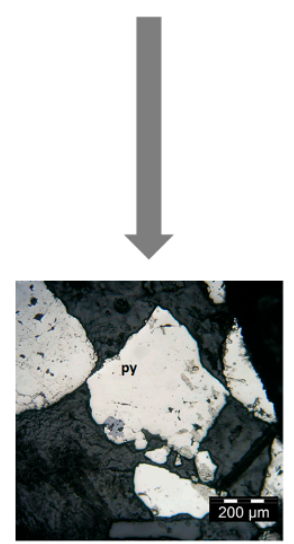

Pyrite after leaching (6h)
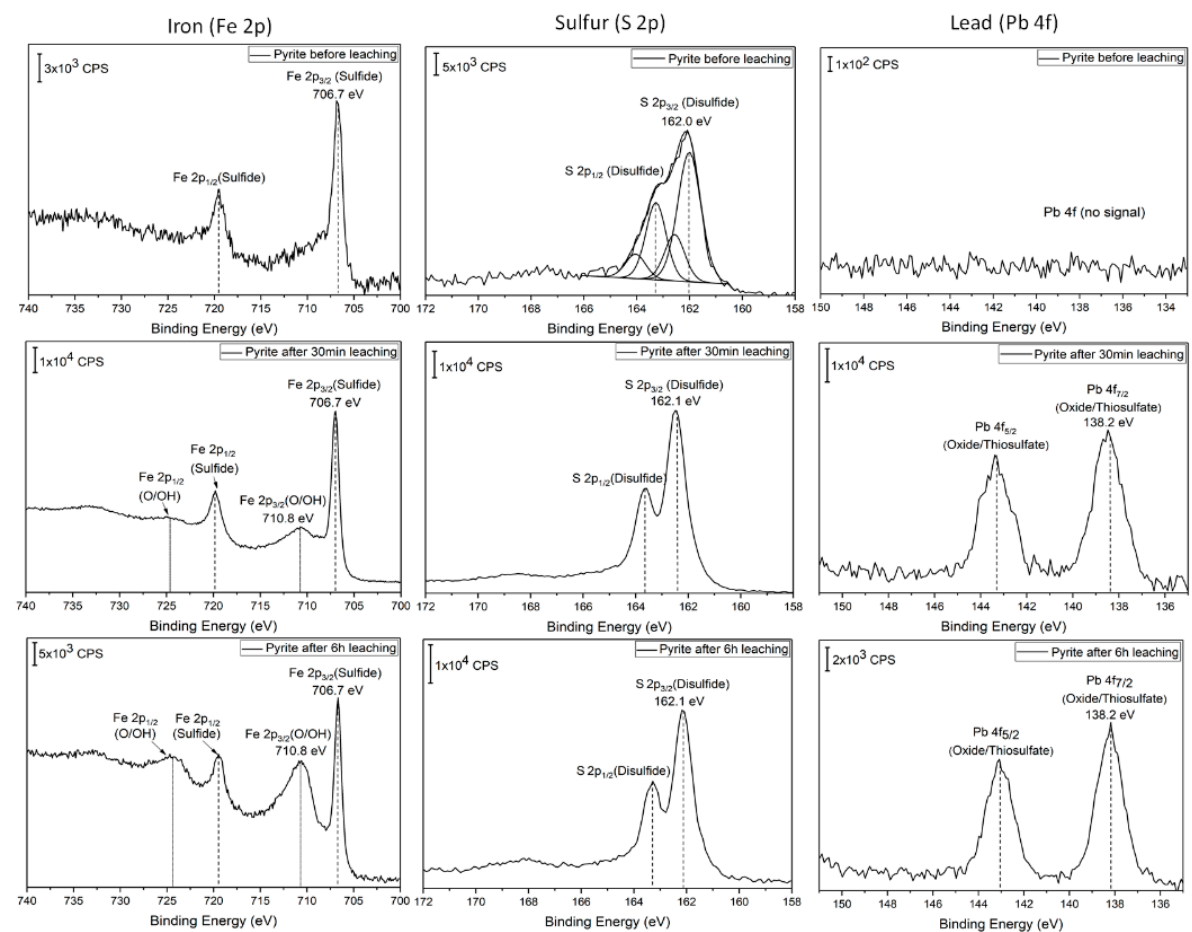

Figure 1. Changes observed during cyanidation of pyrite. The top panels represent the initial results of characterization with polarization microscopy (left) and XPS signals for iron, sulfur and lead (from left to right). The middle panels correspond to XPS signals after the first $30 \mathrm{~min}$ of leaching and the bottom panels show the state of the pyrite grain investigated with PM and XPS after six-hour leaching.

To better identify the nature of the lead layer grown on the pyrite surface, a different grain was also followed during cyanidation, namely the one corresponding to pyrite with inclusions of galena. Identification of this grain was possible with PM, and micrographs are shown in Figure 2. Before leaching, iron is mostly present as pyrite, as evidenced by the sharp peaks in the Fe $2 \mathrm{p}_{3 / 2}$ region at $706.8 \mathrm{eV}$ corresponding to sulfide. Lead, on the other side, shows a broad signal which suggests the presence of sulfides and sulfates ( 137.4 and $138.5 \mathrm{eV}$, respectively) and, indeed, the $S 2 p_{3 / 2}$ signal shows the presence of small amounts of sulfates on the surface. After a six-hour leaching, the PM micrographs show evidence of a reaction, which promoted the loss of portions of the grain, particularly associated with galena. This suggests that leaching of galena, given by Equations (1)-(3), takes place at a fast rate, likely due to the formation of a galvanic pair pyrite-galena, which enhances the reactivity of galena while pyrite becomes more inert [21].

As observed in Figure 1 for a pure grain of pyrite, the XPS data in Figure 2 shows that iron oxide is produced as a result of leaching ( $\mathrm{Fe} 2 \mathrm{p}_{3 / 2}$ signal at $\left.710.8 \mathrm{eV}\right)$. The surface concentration of lead varies from $20.90 \mathrm{At} \%$ in the original sample to 34.96 and $26.59 \mathrm{At} \%$ after $30 \mathrm{~min}$ and $6 \mathrm{~h}$ of leaching, respectively. In this case, however, the surface concentration of lead is only of relative importance, since lead is present before and after the reaction. The most important feature in XPS is the narrowness of the signal for lead $\left(\mathrm{Pb} \mathrm{2} \mathrm{p}_{7 / 2}\right)$ at $138.1 \mathrm{eV}$, a position which was not associated with sulfides nor sulfates. According to the literature, this position can be attributed to oxides and/or thiosulfates $[18,22]$ and evidences that new lead species are present on the surface while sulfides and sulfates are leached out. This fact is noticeable when inspecting the micrographs in Figure 2. It is important to highlight that in spite of the similar surface concentration of lead throughout the leaching process, the intensity of the $\mathrm{Pb} 4 \mathrm{f}_{7 / 2}$ signal shows approximately a ten-fold increase with respect to the original mineral, further supporting the fact that lead re-adsorbs on the pyrite surface. This experiment confirms that the position of the peak corresponding to adsorbed lead $(138.2 \mathrm{eV})$ in Figure 1 cannot be assigned to sulfide or sulfate. 

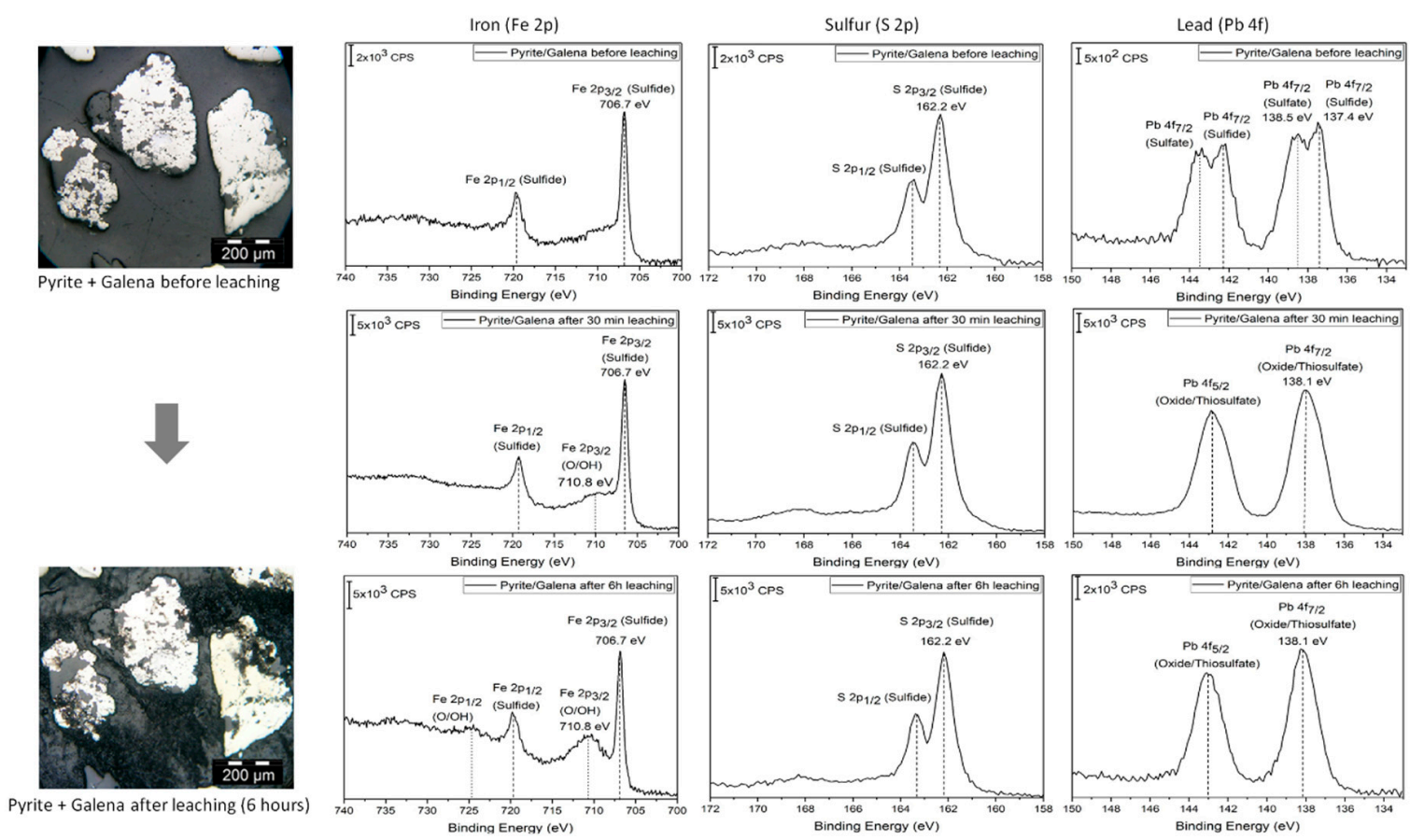

Figure 2. Changes observed during cyanidation of pyrite with inclusions of galena. The top panels represent the initial results of characterization with polarization microscopy (left) and XPS signals for iron, sulfur and lead (from left to right). The bottom panels show the state of the grain after a six-hour leaching with PM and XPS. The high reactivity of galena inclusions leads to the loss of portions of the grain after leaching.

Re-adsorption is a spontaneous process which depends on the affinity of the adsorbate to interact with a surface. Therefore, it can be expected that it is not a universal process which can happen on all surfaces. Indeed, Figure 3 shows that covellite does not feature significant evidence of lead re-adsorption. From our XPS measurements, the signals of lead after $30 \mathrm{~min}$ and $5 \mathrm{~h}$ represent only $\sim 5$ at $\%$. The intensity of the areas of lead on covellite with respect to the case of pyrite and pyrite-galena is significantly smaller, which also supports the case that on this mineral the re-adsorption is significantly smaller. According to Breuer [23], covellite is leached using cyanide following the reaction below:

$$
2 \mathrm{CuS}+5 \mathrm{CN}^{-}+\mathrm{H}_{2} \mathrm{O}=2 \mathrm{Cu}(\mathrm{CN})_{2}{ }^{-}+\mathrm{SCN}^{-}+\mathrm{OH}^{-}+\mathrm{SH}^{-}
$$

This is a reductive dissolution mechanism, where copper passes from $\mathrm{Cu}^{+2}$ in covellite to $\mathrm{Cu}^{+1}$ in the cyanide complex. The leaching of covellite is possible but the process is slow, hence the clear change in the PM micrograph as the reaction proceeds (from an original white color to a tarnished surface) without seeing a damaged surface as in the case of galena. It may be likely that in the case of covellite, which presents an intermediate reactivity between that of pyrite (essentially inert) and galena (highly reactive in presence of pyrite), the leaching reaction is sufficiently fast to impede the adsorption of lead species.

Since lead re-adsorption was observed to be a selective process, taking place preferably over pyrite surfaces, it was expected to be also observed on the fine-milled, pyrite-based mineral entering the industrial leaching circuit. Indeed, leaching experiments done with non-embedded samples also showed evidence of lead re-adsorption (Figure S3). In accordance with the data in Figure 2, the two original $\mathrm{Pb} 4 \mathrm{f}_{7 / 2}$ peaks, associated with lead sulfide and sulfate (137.4 and $138.5 \mathrm{eV}$, respectively), become less intense as a new component, located at $138.1 \mathrm{eV}$, which rises during leaching. This data will be further discussed in the light of silver extraction and cyanide consumption in a separate work. 


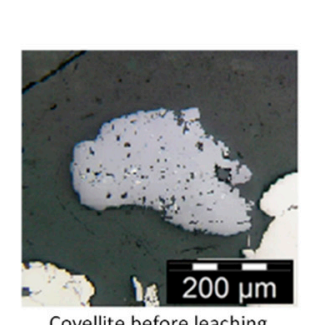

Covellite before leaching
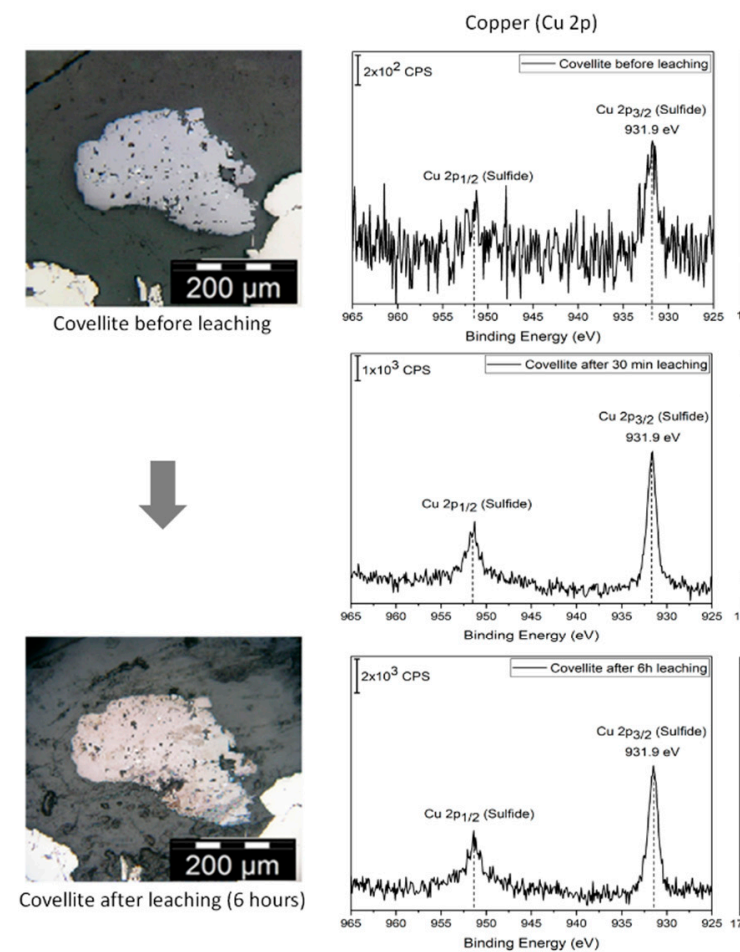
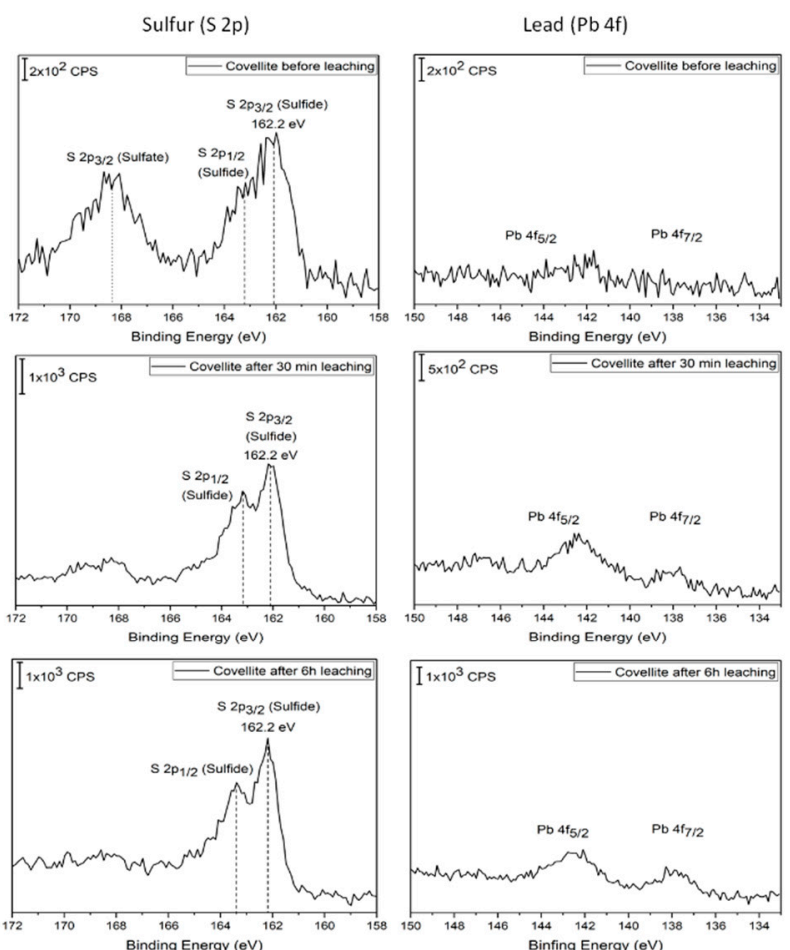

Figure 3. Changes observed during cyanidation of covellite. The top panels represent the initial results of characterization with polarization microscopy (left) and XPS signals for copper, sulfur and lead (from left to right). Identification of copper and sulfur species goes beyond the goal of this work, and they are reported collectively as "sulfide". The middle panels correspond to XPS signals after the first 30 min of leaching and the bottom panels show the state of the pyrite grain investigated with PM and XPS after six-hour leaching. In this case there is no evidence of lead re-adsorption.

\section{Summary and Outlook}

Through three relatively simple examples, it has been demonstrated that re-adsorption of lead takes place during cyanide leaching of a polymetallic sulfide. This process cannot be identified easily with traditional techniques for mineral characterization (such as polarization microscopy and scanning electron microscopy) since they are not sufficiently surface-sensitive. Polarization microscopy allows for a rapid identification of mineralogical species, while X-ray photoelectron spectroscopy can identify chemical changes on a surface. By working with minerals from polished sections, it is possible to monitor in time the response of a specific mineral towards a hydrometallurgical agent. In some cases, as in Figure 2, the response of minerals is easily observed simply using polarization microscopy. However, in other cases, as in Figure 1, the mineral seems unreactive towards a hydrometallurgical agent by polarization microscopy. In this case, XPS proves to be an important tool for identifying surface processes such as the re-adsorption of leached metals. The impact of lead re-adsorption on the metallurgical behavior of the ore (silver extraction with cyanidation and consumption of cyanide) will be the subject of a separate publication.

Supplementary Materials: The following are available online at http:/ /www.mdpi.com/2075-163X/8/10/427/s1, Figure S1: Polarization micrographs of minerals within the samples ore, Figure S2: Comparison of micrographs from polarization microscopy and from the camera coupled to the XPS system, Figure S3: XPS data for free mineral particles before and after leaching, showing that re-adsorption of lead also takes place in the absence of resin.

Author Contributions: J.C.F.R.-R. and A.V.T. conceived and designed the experiments; D.S.-Q., C.H. and M.J.-C. performed the experiments; D.S.-Q., C.H., M.J.-C., C.B., A.V.T. and J.C.F.R.-R. analyzed the data and wrote the paper.

Funding: This research was supported by Peru's National Council for Science, Technology and Technological Innovation (FONDECYT-CONCYTEC) and the British Embassy in Lima (contracts 154-2015 and 002-2016), as well 
as by the Phosagro/UNESCO/IUPAC Partnership in Green Chemistry for Life (Contract 4500245048). The authors acknowledge the NSF $(9724307 ; 1428149)$ and the NIH NIGMS COBRE program (P30-GM110758) for partial support of activities in the University of Delaware Surface Analysis Facility.

Acknowledgments: We acknowledge the support of Volcan Cía. Minera for facilitating the ore samples employed in this research. Luis Loaiza (Volcan) is especially thanked for his decisive support for this academia-industry collaboration. D.S.-Q. acknowledges the support provided by the Department of Chemistry and Biochemistry at the University of Delaware during her stay in the USA. Humberto Chirif, Renzo Portilla and Karinna Visurraga (UTEC) are acknowledged for useful discussions and suggestions. Karinna Visurraga is also acknowledged for technical and administrative support.

Conflicts of Interest: The authors declare no conflict of interest. The funding sponsors had no role in the design of the study; in the collection, analyses, or interpretation of data; in the writing of the manuscript, and in the decision to publish the results.

\section{References}

1. Baum, W. Ore characterization, process mineralogy and lab automation a roadmap for future mining. Miner. Eng. 2014, 60, 69-73. [CrossRef]

2. Klein, C.; Philpotts, A.R. Earth Materials_Introduction to Mineralogy and Petrology, 2nd ed.; Cambridge University Press: New York, NY, USA, 2012; ISBN 9780521761154.

3. Celep, O.; Devec, H.; Vicil, M. Characterization of refractory behaviour of complex gold/silver ore by diagnostic leaching. Trans. Nonferr. Met. Soc. China 2008, 19, 707-713. [CrossRef]

4. Rees, K.L.; Van Deventer, J.S.J. Preg-robbing phenomena in the cyanidation of sulphide gold ores. Hydrometallurgy 2000, 58, 61-80. [CrossRef]

5. Mwase, J.M.; Petersen, J. Characterizing the leaching of sperrylite (PtAs 2) in cyanide-based solutions. Hydrometallurgy 2017. [CrossRef]

6. Parker, A.; Klauber, C.; Kougianos, A.; Watling, H.R.; Van Bronswijk, W.; Parker, A.J. An X-ray photoelectron spectroscopy study of the mechanism of oxidative dissolution of chalcopyrite. Hydrometallurgy 2003, 71, 265-276. [CrossRef]

7. Boulton, A.; Fornasiero, D.; Ralston, J. Characterisation of sphalerite and pyrite flotation samples by XPS and ToF-SIMS. Int. J. Miner. Process. 2003, 70, 205-219. [CrossRef]

8. Jiang, H.; Xie, F.; Dreisinger, D.B. Comparative study of auxiliary oxidants in cyanidation of silver sulfide. Hydrometallurgy 2015, 158, 149-156. [CrossRef]

9. Bas, A.D.; Ghali, E.; Choi, Y. A review on electrochemical dissolution and passivation of gold during cyanidation in presence of sulphides and oxides. Hydrometallurgy 2017, 172, 30-44. [CrossRef]

10. Derycke, V.; Kongolo, M.; Benzaazoua, M.; Mallet, M.; Barrès, O.; De Donato, P.; Bussière, B.; Mermillod-Blondin, R. Surface chemical characterization of different pyrite size fractions for flotation purposes. Int. J. Miner. Process. 2013, 118. [CrossRef]

11. Jeffrey, M.I.; Breuer, P.L. Cyanide leaching of gold in solutions containing sulfide. Miner. Eng. 2000, 13, 1097-1106. [CrossRef]

12. Senanayake, G. A review of effects of silver, lead, sulfide and carbonaceous matter on gold cyanidation and mechanistic interpretation. Hydrometallurgy 2008, 90, 46-73. [CrossRef]

13. Harmer, S.L.; Thomas, J.E.; Fornasiero, D.; Gerson, A.R. The evolution of surface layers formed during chalcopyrite leaching. Geochim. Cosmochim. Acta 2006, 70, 4392-4402. [CrossRef]

14. Lane, G.R.; Martin, C.; Pirard, E. Techniques and applications for predictive metallurgy and ore characterization using optical image analysis. Miner. Eng. 2008, 21, 568-577. [CrossRef]

15. Smart, R.S.C.; Skinner, W.M.; Gerson, A.R. XPS of sulphide mineral surfaces: Metal-deficient, polysulphides, defects and elemental sulphur. Surf. Interface Anal. 1999. [CrossRef]

16. Mills, P.; Sullivan, J.L. A study of the core level electrons in iron and its three oxides by means of X-ray photoelectron spectroscopy. J. Phys. D Appl. Phys. 1983, 16, 723-732. [CrossRef]

17. Bastl, Z.; Republic, C. X-ray photoelectron spectroscopy study of galena dissolution in ferric chloride media. J. Mater. Sci. Lett. 1993, 12, 789-790. [CrossRef]

18. Abdel-Samad, H.; Watson, P.R. An XPS study of the adsorption of lead on goethite (alpha-FeOOH). Appl. Surf. Sci. 1998, 136, 46-54. [CrossRef] 
19. La Brooy, S.R.; Linge, H.G.; Walker, G.S. Review of gold extraction from ores. Miner. Eng. 1994, 7, $1213-1241$. [CrossRef]

20. Prestidge, C.A.; Ralston, J.; Smart, R.S.C. The role of cyanide in the interaction of ethyl xanthate with galena. Colloids Surf. Physicochem. Eng. Asp. 1993, 81, 103-119. [CrossRef]

21. Aghamirian, M.M.; Yen, W.T. Mechanisms of galvanic interactions between gold and sulfide minerals in cyanide solution. Miner. Eng. 2005, 18, 393-407. [CrossRef]

22. Manocha, A. Flotation related ESCA studies on PbS surfaces. Appl. Surf. Sci. 1977, 1, 129-141. [CrossRef]

23. Breuer, P.L.; Dai, X.; Jeffrey, M.I. Leaching of gold and copper minerals in cyanide deficient copper solutions. Hydrometallurgy 2005, 78, 156-165. [CrossRef]

(C) 2018 by the authors. Licensee MDPI, Basel, Switzerland. This article is an open access article distributed under the terms and conditions of the Creative Commons Attribution (CC BY) license (http://creativecommons.org/licenses/by/4.0/). 